\title{
TEMPERATURE MEASUREMENT IN SOLAR THERMAL APPLICATIONS
}

\author{
Paul Refalo ${ }^{1}$, Robert Ghirlando ${ }^{1}$ and Stephen Abela ${ }^{2}$ \\ ${ }^{1}$ Department of Mechanical Engineering, University of Malta, Msida (Malta), email: paul.refalo@um.edu.mt \\ 2 Department of Metallurgy and Materials Engineering, University of Malta, Msida (Malta)
}

\begin{abstract}
While measuring the temperature of a fluid such as air or water which is exposed to solar radiation, the temperature measuring device, such as a thermocouple, should be shielded from incident irradiance. The probe should be well ventilated in order to increase heat transfer by convection and thus get a reading closer to the true temperature. The popular Stevenson screen which is used for meteorological air temperature measurement consists of a cage with horizontal louvers. This makes it too bulky to use in enclosures such as solar collectors. In this study, various shields have been analysed under laboratory conditions using a halogen lamp as a source of infrared radiation.
\end{abstract}

The standard on Guidance for Solar Radiation Testing (60068-2-9:2000) suggests to use a thermocouple freely mounted in a radiation shield comprising a cupro-nickel tube. However experimental results show that the thermocouple reading resulted in $9^{\circ} \mathrm{C}$ higher than the true air temperature. Other radiation shields consisting of white vertical PVC tubes, varying in length and diameter, resulted in a temperature increase of $3-5^{\circ} \mathrm{C}$. The closest temperature reading was achieved by using a longitudinally slit tube as the radiation screen. This resulted in a discrepancy of around $1-3^{\circ} \mathrm{C}$ higher than the true temperature. It was observed that the difference between the true temperature and the reading from the shielded thermocouple decreases with increasing both length and diameter of the slit tube.

\section{Introduction}

Temperature measuring devices exchange heat via the main three modes of heat transfer, namely conduction, convection and radiation, to reach thermal equilibrium with the medium being investigated. When thermal equilibrium is reached, the temperature of the probe and that of the surrounding fluid or material are similar, (ideally identical). However, in the presence of thermal radiation, the sensing tip of a temperature measuring device never reaches thermal equilibrium. This results in the thermocouple reading higher values than the true fluid temperature.

In order to measure the ambient air temperature, the measuring instrument in meteorological data acquisition systems, needs to be shielded from solar radiation. The Stevenson Screen, developed in 1864, comprises horizontal louvers to enhance ventilation as shown in Figure 1 (Erell et al., 2003). As wind flows through the cage, convective heat transfer from the instrument is enhanced and the difference between the temperature of the device and the true ambient temperature is minimised, giving a more accurate reading.

However, to measure the air temperature inside solar thermal units, the Stevenson configuration is too cumbersome to install. The naturally induced convection currents due to the buoyancy effect in such applications are in the vertical direction. Since the louvers in the Stevenson cage are horizontal, naturally induced convention currents are suppressed. The World Meteorological Organization (WMO) suggests to apply forced ventilation when the microclimate inside the screen differs from the surrounding conditions in ambient temperature measurements (WMO, 2008). However, forced convection in radiation shields installed inside solar thermal applications alters the macro mechanism of the application itself and thus cannot be used. 


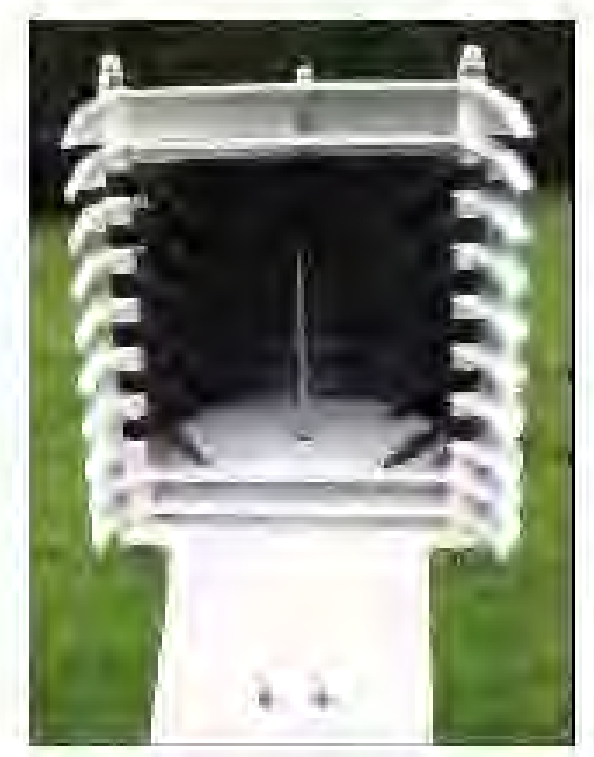

Figure 1: Cross-sectional view of a Stevenson Screen (Campbell, 2010)

The WMO recommends a highly polished metal radiation screen so that the solar absorptivity is kept low. However where the temperature measuring system relies on natural ventilation, thermally insulating material is suggested (WMO, 2008). The size and construction of the screen should be kept small in order to keep the thermal capacity low. On the other hand the British Standard on solar radiation testing published in 2000 had suggested using a thermocouple freely mounted in a white painted cupro-nickel tube $(15 \mathrm{~mm}$ diameter and $70 \mathrm{~mm}$ long) surmounted by a spaced metal hood (BS, 2000). The standard published in 2000 has been superseded by a newer version published in June 2011 (BS, 2011). The latter recommends to adequately shielding temperature sensors from radiation; however the details about the shield design mentioned in the 2000 standard have been omitted.

\section{Method}

Various radiation shields have been designed, manufactured and tested. The design of the shields and the experimental procedures shall be described.

\subsection{Radiation Shields}

\subsubsection{Copper Shields}

As suggested by the British Standard (BS, 2000) a shield comprising a 70mm long copper pipe ( $\varnothing 15)$ was designed. The upper part of the pipe was cut so as to leave four $1 \mathrm{~mm}$ wide, $10 \mathrm{~mm}$ long protruding struts as shown in Figure 2. The circumferential 10mm gap at the top of the pipe was intended to enhance ventilation in the vertical direction. A circular disc made of copper was brazed to the struts to act as a hood and prevent irradiative exposure of the inner surface of the tube. The diameter of the hood, $\mathrm{D}_{\text {hood }}$ was calculated so as to shade the pipe for solar altitudes greater than $25^{\circ}$ to the horizontal. For a $10 \mathrm{~mm}$ gap, the minimum diameter was found to be $60 \mathrm{~mm}$. However this resulted in a horizontal plate thermally connected to the copper pipe. When exposed to solar irradiance, although painted white, the hood would act as an absorber, increasing the temperature of the whole shield. 
In order to minimise both solar absorption and thermal capacity of the shield, the diameter of the hood was reduced to $20 \mathrm{~mm}$, and the length of the pipe, $\mathrm{L}$, to $40 \mathrm{~mm}$. In order to increase heat transfer by convection, a slit in the pipe was cut. When used in solar applications, such a shield has to be installed with the slit facing north to make sure that both the inner surface of the pipe and the thermocouple are not exposed to solar irradiance.

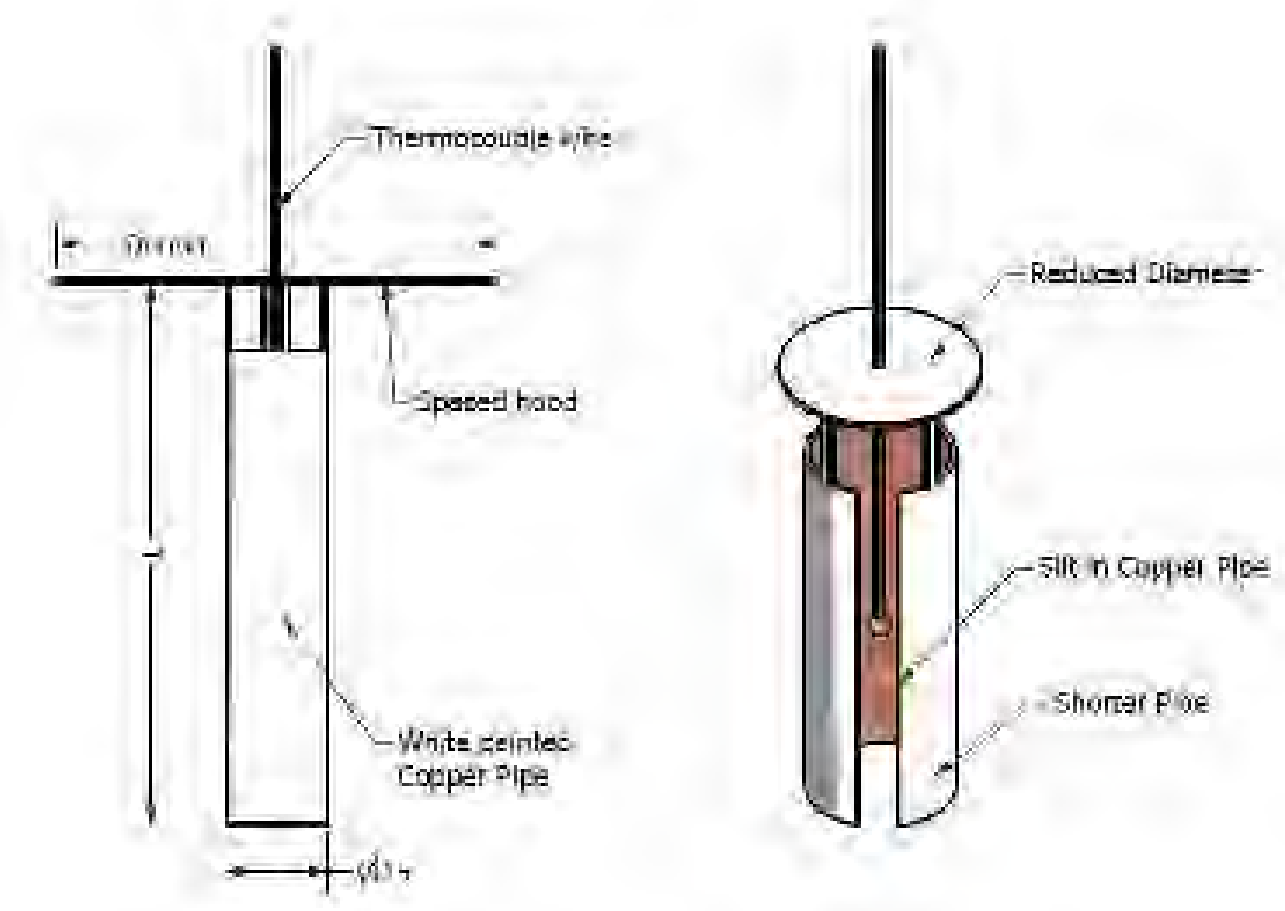

Figure 2: Copper Radiation Shields

\subsubsection{Polymer Shields}

In order to further reduce the thermal capacity of the shield and abide by the suggestions of the WMO, a radiation shield made out of white UV stabilised polyvinyl chloride (PVC) was designed, as depicted in Figure 3. The slit aperture was increased to $110^{\circ}$. In summer in Malta (latitude $=36^{\circ} \mathrm{N}$ ), the sun covers $240^{\circ}$ azimuthally. Therefore, an aperture of $110^{\circ}$ ensures that that the suspended thermocouple is always shielded from radiation. The horizontal hood described above, was replaced by a spaced aluminium foil cone cover. The space between the pipe and the cone cover enhances vertical convection. The PVC pipe was suspended from two small holes drilled in the PVC pipe. A fine wire was passed through the same hole used for the thermocouple.

Various PVC shields of different diameter D (20-50mm), and Length L (40,100mm), were manufactured in order to analyse the effect of the varying dimensions. 


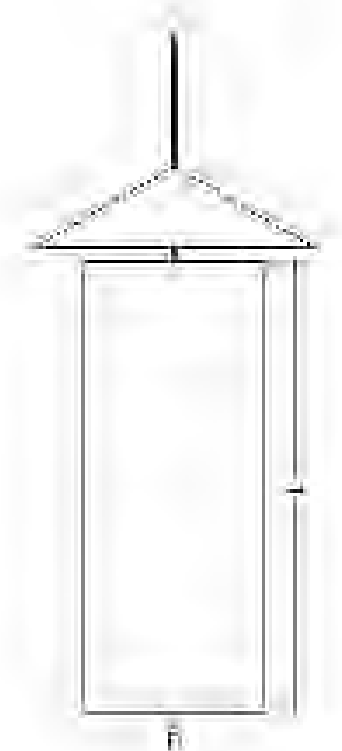

(a)

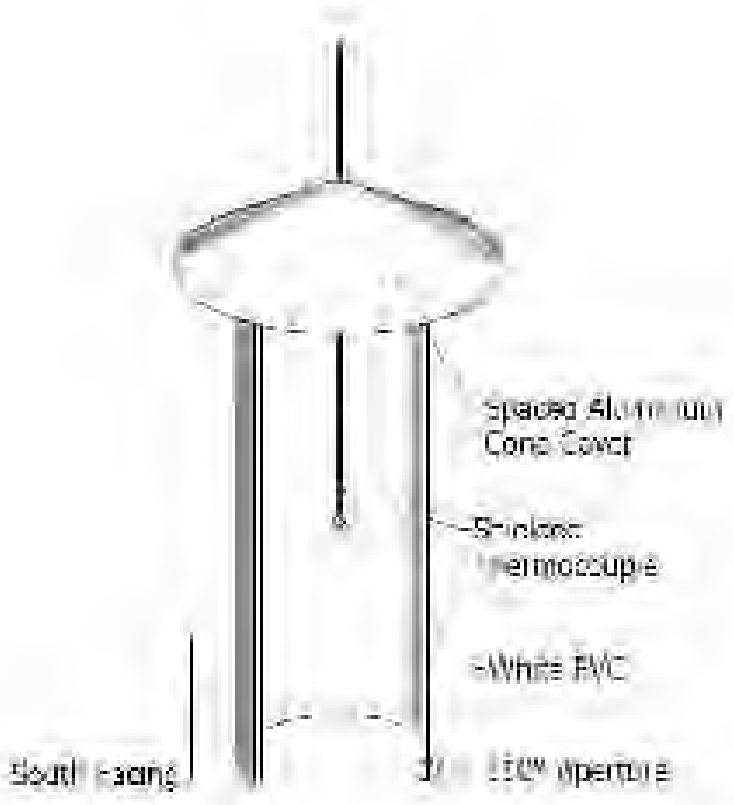

(b)

Figure 3: PVC Radiation Shields

(a) Front View of Full Pipe PVC Radiation Shield (b) 3D View of PVC shield with slit aperture

\subsection{Experimental Procedure}

The setup shown in Figure 1 was installed. A 35W halogen lamp was used as a source of thermal radiation. The lamp was installed in a copper pipe made out of a rolled copper sheet of $0.1 \mathrm{~mm}$ thickness. The inside surface of the pipe was painted white in order to increase the reflectivity (72\%) and thus minimise the thermal absorptivity and heat gain from the lamp. The outside surface was highly polished in order to reduce the thermal emissivity (3\%) and the heat transfer by radiation from the lamp copper shield. The whole experimental setup was installed on a bench covered by a black textile material in order to minimise the reflectivity from the bench to the thermocouples.

Type $\mathrm{T}$ - Class 1 thermocouples with an accuracy of $\pm 0.5^{\circ} \mathrm{C}$ were used. One thermocouple was used to measure ambient air temperature, $\mathrm{T}_{1}$. Another one was freely suspended in a radiation shield in order to measure the temperature of the air, $\mathrm{T}_{3}$ heated by thermal radiation but shielded from direct radiation from the lamp. The thermocouple wire was inserted in the shield such that thermocouple bead was at the centre of the shield as depicted in Figure 2 and Figure 3. The distance between the halogen lamp and the radiation shield was kept constant in order to keep the radiation incident on the shields constant. A fine wire mesh was used so that when the radiation shield was changed, the setup was installed at the same location relative to the lamp.

As the air molecules in front of the lamp were radiated, the air density decreased due to the increase in temperature and so an upward convection current was induced. The third thermocouple was installed above the radiation shield setup at a point which was not radiated by the lamp. This temperature reading, $\mathrm{T}_{2}$, was considered to be the closest to the true air temperature. The thermocouples were connected to a datalogger which was programmed to take record readings every two seconds. 


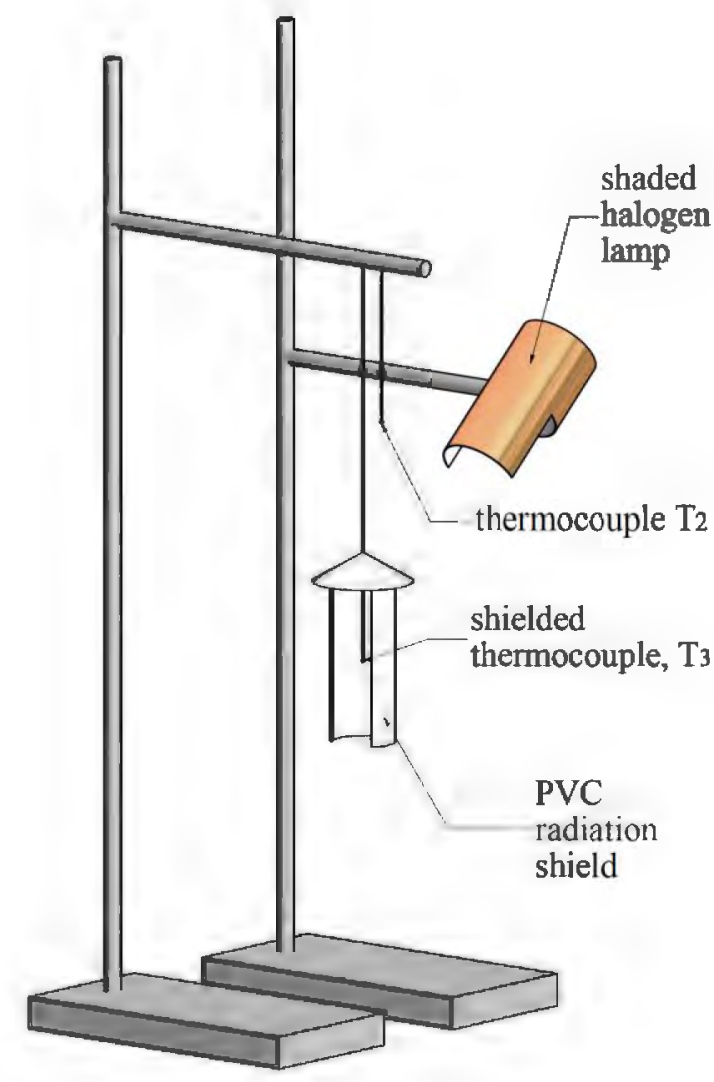

Figure 4: Schematic diagram of the experimental setup

The experiment was repeated for the cases tabulated in Table 1.

Table 1: List of different radiation shields

\begin{tabular}{|c|l|}
\hline $\begin{array}{c}\text { Case } \\
\text { Number }\end{array}$ & Description \\
\hline 1 & Exposed brown thermocouple \\
\hline 2 & Exposed white thermocouple \\
\hline 3 & Brown thermocouple in white painted copper pipe $\left(\mathrm{L}=40,70 \mathrm{~mm}, \mathrm{D}_{\text {hood }}=60 \mathrm{~mm}\right)$ \\
\hline 4 & Brown thermocouple in white painted copper pipe $\left(\mathrm{L}=40 \mathrm{~mm}, \varnothing \mathrm{D}_{\text {hood }}=20 \mathrm{~mm}\right)$ \\
\hline 5 & Brown thermocouple in white painted copper pipe with slit $\left(\mathrm{L}=40,70 \mathrm{~mm}, \mathrm{D}_{\text {hood }}=20 \mathrm{~mm}\right)$ \\
\hline 6 & Brown thermocouple in full white PVC pipe $(\mathrm{L}=40,100 \mathrm{~mm}, \varnothing 20-50 \mathrm{~mm})$ \\
\hline 7 & Brown thermocouple in white PVC pipe with slit $(\mathrm{L}=40,100 \mathrm{~mm}, \varnothing 20-50 \mathrm{~mm})$ \\
\hline 8 & White thermocouple in white PVC pipe with slit $(\mathrm{L}=40,100 \mathrm{~mm}, \varnothing 20-50 \mathrm{~mm})$ \\
\hline
\end{tabular}

Once a different shield was setup the system was allowed to reach thermal equilibrium. The temperatures mentioned above were measured for thirty minutes. All the doors and windows in the room were closed to ensure that there were no forced convection currents. The temperature differences for the different setups are shown and discussed in the sections below. 


\section{Uncertainty Analysis}

Since for each case, hundreds of temperature readings were recorded, the experiment is considerer to be a multiple measurement experiment.

Let $T=T_{3}-T_{2} \quad$ (eq. 1$)$

For a multiple measurement experiment (Holman, 2001):

$\varepsilon T=\left(\frac{\partial T}{\partial T_{3}}\right)^{2} \varepsilon T_{3}^{2}+\left(\frac{\partial T}{\partial T_{2}}\right)^{2} \varepsilon T_{2}^{2} \quad$ (eq. 2)

Where $\varepsilon T$ is the estimated uncertainty in $T$.

Since the expected error from Class $1-$ Type $\mathrm{T}$ thermocouples is $0.5^{\circ} \mathrm{C}, \varepsilon \mathrm{T}=0.71^{\circ} \mathrm{C}$. For each set of readings, it was made sure that the standard deviation of $\mathrm{T}$ was less than one third of $0.71(0.24)$ to ensure that $99.6 \%$ of the values lie within experimental error limits.

\section{Results}

For each radiation shield a graph similar to Graph 1 was plotted. The temperature difference was calculated and plotted as shown. The followed profile was the same in all cases but only one example is shown here.
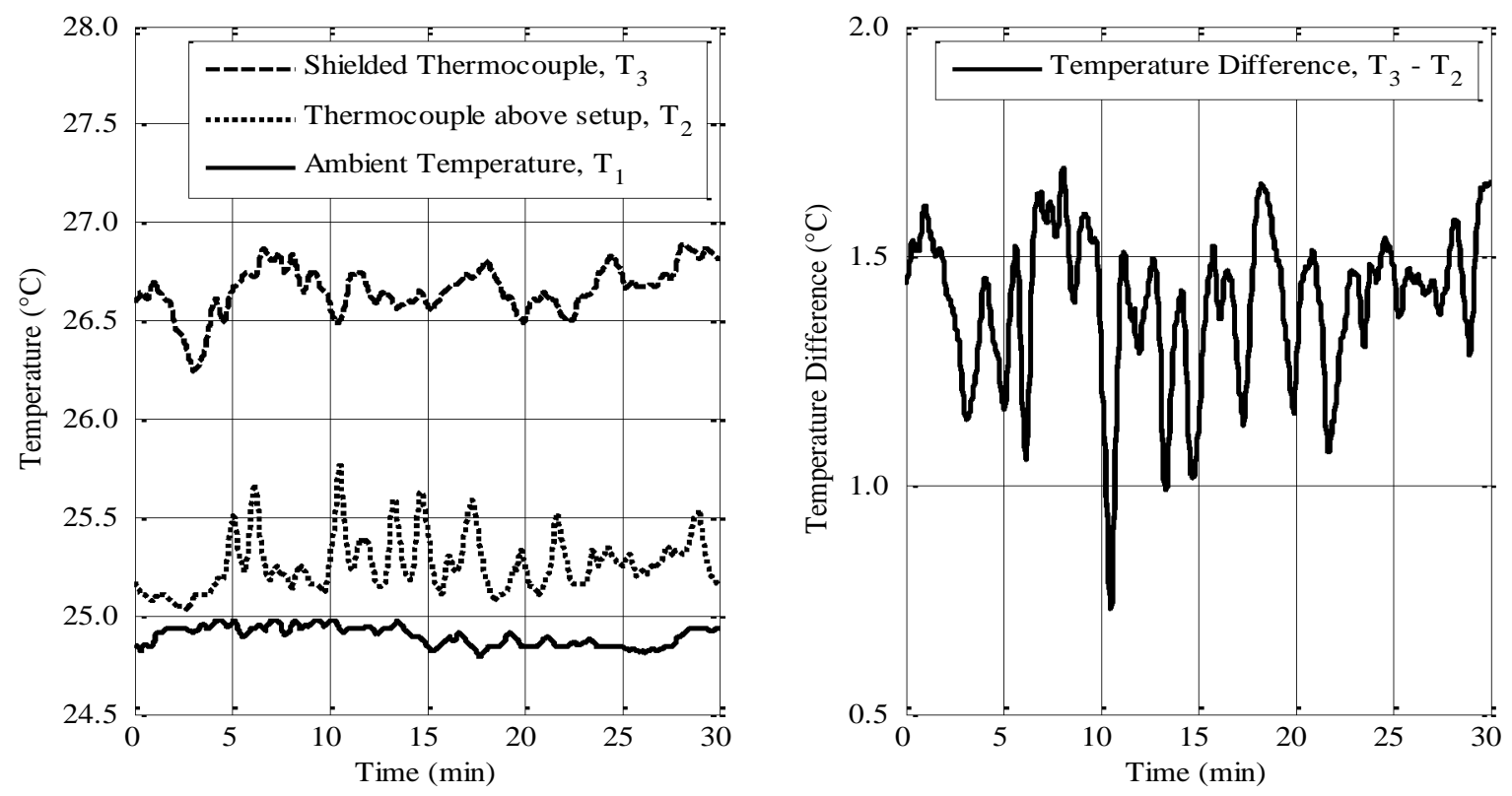

Graph 1: Temperature measurements for Case 7 with $\mathrm{L}=100 \mathrm{~mm}, \varnothing 50 \mathrm{~mm}$

The average temperature differences for various shields are plotted in Graph 2 below. Reference is made to Table 1. 


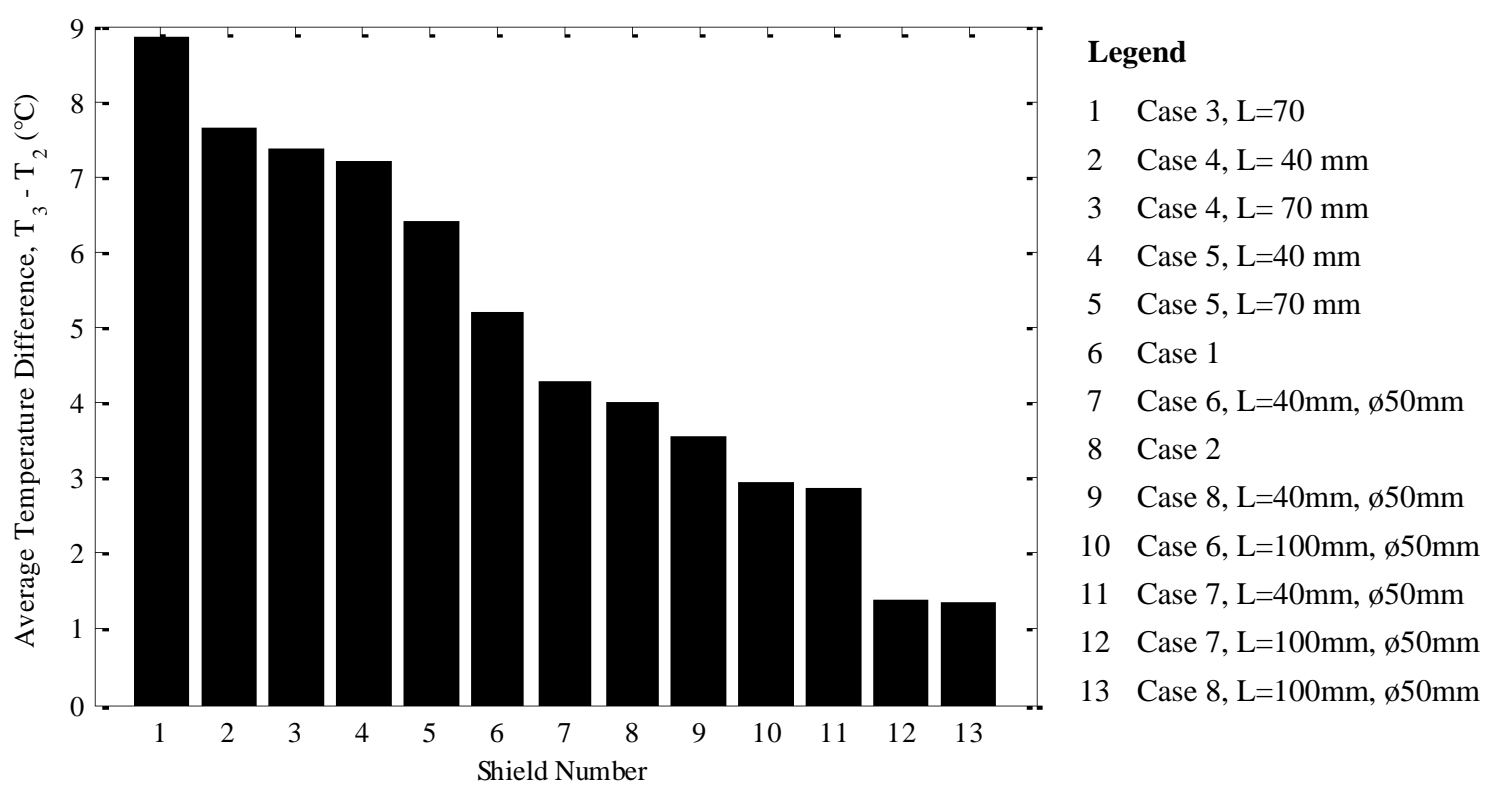

Graph 2: Average temperature difference for different radiation shields

Since lower temperature differences were achieved when using PVC shields, the dimensions of the pipe were varied (Case numbers 6-8). The resulting temperature differences are shown in the graphs below.

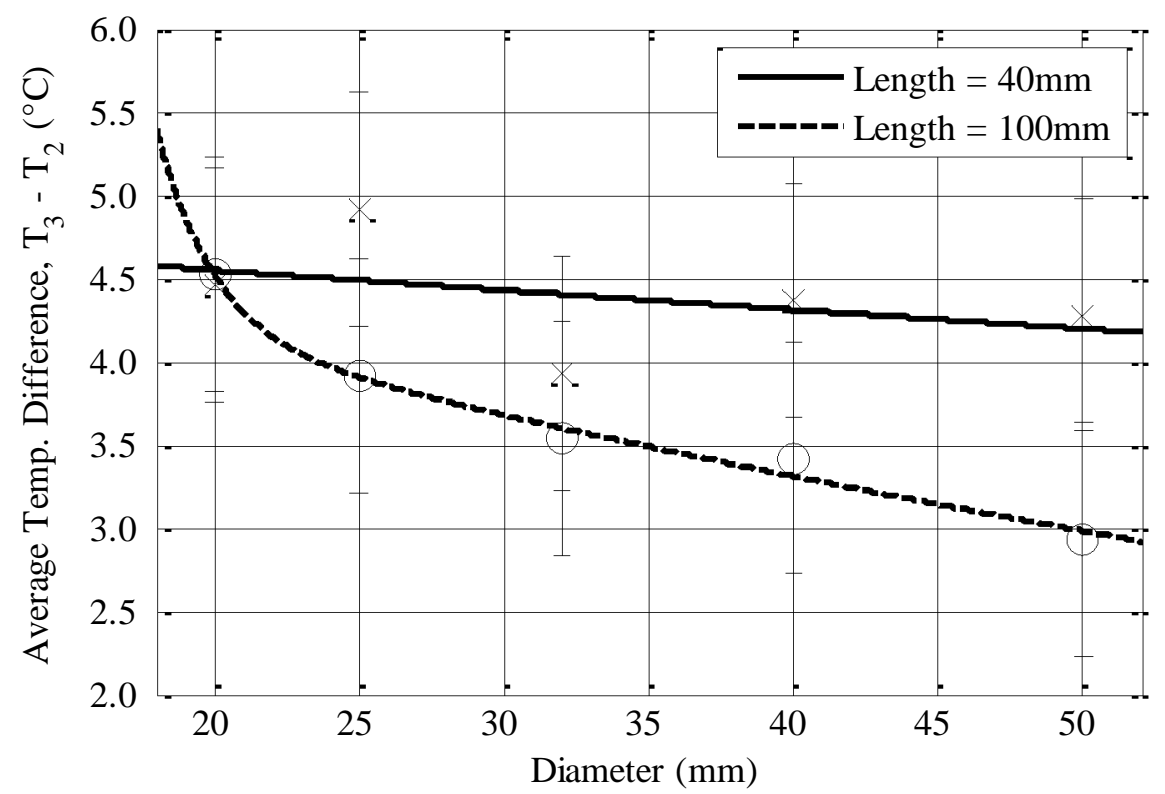

Graph 3: Average temperature difference for Case 6 with $L=40,100 \mathrm{~mm}, \varnothing 20-50 \mathrm{~mm}$ 


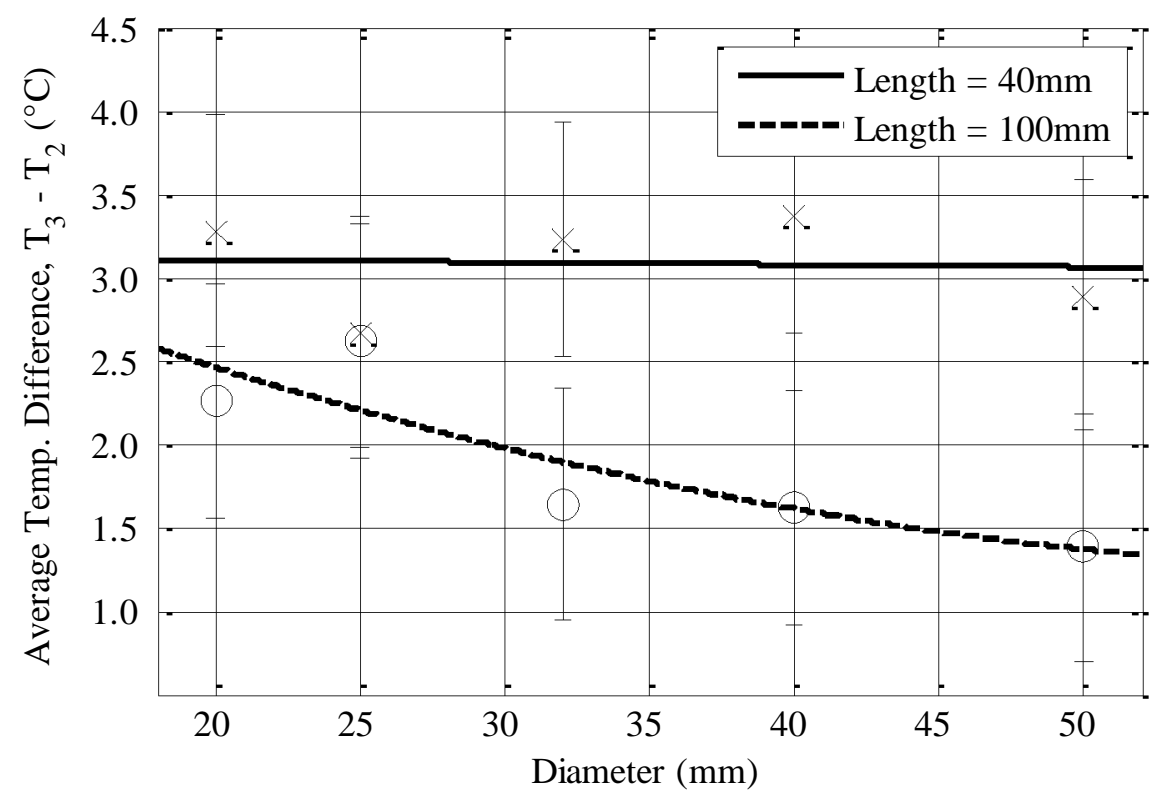

Graph 4: Average temperature difference for Case 7 with $L=40,100 \mathrm{~mm}, \emptyset 20-50 \mathrm{~mm}$

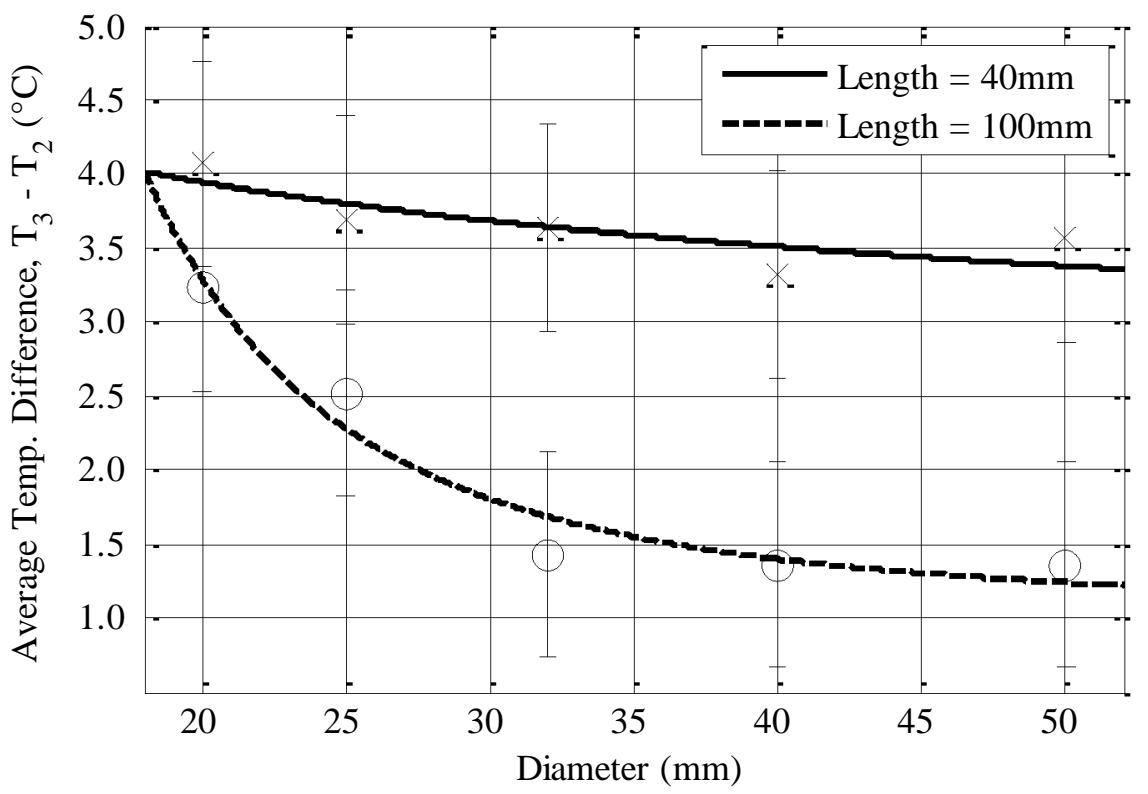

Graph 5: Average temperature difference for Case 8 with $\mathrm{L}=40,100 \mathrm{~mm}, \varnothing 20-50 \mathrm{~mm}$

\section{Discussion}

From a typical specification sheet of a Stevenson cage (Campbell, 2010), one could note that manufacturers specify that for small radiation shields, at high solar radiation and wind speed less than $1 \mathrm{~m} / \mathrm{s}$, the temperature reading could be higher by $0.75^{\circ} \mathrm{C}$. In the cases in which shields similar to those described in this paper are used, the velocity of the naturally induced convection currents could be less than that. Also, in order not to be too cumbersome, the shields have to be small.

It is evident from Graph 1 that the reading from the shielded thermocouple $T_{3}$ is always higher than the reading from the thermocouple above the setup $\mathrm{T}_{2}$. This shows that the radiation shield which is exposed to radiation, transfers heat mainly by convection to the thermocouple inside it. Another point to note from the same graph is the fact that, as expected, the temperature above the setup is higher than the ambient 
temperature $\mathrm{T}_{1}$ inside the room. This shows that the air under thermal radiation was being heated up. Thus, taking $\mathrm{T}_{2}$ as the datum to find the temperature rise inside the shield was a better approximation than the ambient temperature.

The copper shield suggested in the British standard resulted in a temperature difference of over $7^{\circ} \mathrm{C}$. The highest temperature rise of $8.9^{\circ} \mathrm{C}$, observed when using a copper pipe (L70mm, $\varnothing 15 \mathrm{~mm}$ ) surmounted by a spaced hood $(\varnothing 60 \mathrm{~mm})$ as shown in Shield 1 of Graph 2. Reducing the diameter of the hood to 20mm (Shield 3 ) resulted in a temperature difference decrease of over $16 \%$ to $7.4^{\circ} \mathrm{C}$. This shows that when the absorbed radiation was reduced by reducing the projected area of the shield, the temperature rise also decreased. The main disadvantage of such a small hood when used to shield solar radiation is that for low angles of solar altitude, the inner surface of the pipe would be exposed directly to irradiation. This would lead to a higher temperature rise and so such a shield is not recommended. Absorbed radiation was further reduced by reducing the length of the shield from 70 to $40 \mathrm{~mm}$ (Shield 2). However the reduction in the average temperature difference recorded when using this shield was negligible, as shown in the graph.

To enhance ventilation a longitudinal slit was cut in the pipe as depicted in Figure 2. When comparing Shield 3 with Shield 5 (the difference between the two is only the slit cut in shield 5), one can note that there was a reduction of $13 \%$ in the temperature rise. This shows that the temperature reading from the thermocouple in shield 5 was closer to the true temperature. However with a temperature difference of over $6^{\circ} \mathrm{C}$, using such a shield, the setup was still unacceptable for measuring the temperature in solar thermal applications.

When an exposed thermocouple was tested, the average temperature rise due to direct exposure to radiation was of $5.2^{\circ} \mathrm{C}$. The copper and constantan wires were soldered, which resulted in a silvery reflective bead. However, the Seebeck effect which is used to generate a voltage in thermocouples does not take place only at the point where dissimilar materials are connected (Recktenwald, 2010). A change in temperature along the thermocouple wires generates a potential difference. Since the absorptivity of the outer sheath of a Type T thermocouple, which is colour-coded brown according to the IEC, is not low, the change in temperature in the irradiated part of the wire was significant. Adding to this, the whole thermocouple was heated since the absorbed radiation was conducted through the metal leads of the wire itself. In order to reduce the absorptivity, both the thermocouple wire and bead were painted white using enamel paint. Although the layer of paint acts as an insulator, in the case where it was exposed to radiation, the temperature rise was reduced to $4^{\circ} \mathrm{C}$; a $23 \%$ reduction when compared to the exposed brown thermocouple.

Graphs 3-5 show the results when using PVC shields. The results when using a full white PVC pipe are shown in Graph 3. Using a PVC shield resulted in a much lower error in the reading. The highest temperature difference recorded was of $4.5^{\circ} \mathrm{C}$, which is $50 \%$ less than that achieved when using shield 1 . It is clear that the longer pipe resulted in closer readings. Adding to this, as the diameter was increased from 20 to $50 \mathrm{~mm}$, the temperature difference decreased by over $35 \%$ from 4.5 to $2.9^{\circ} \mathrm{C}$. For the shorter pipe, the temperature difference was not sensitive to change in diameter. The same trend could also be observed in Graph 4 and Graph 5. Vertically installed shields experience the stack effect in which the air inside the pipe is heated by radiation incident on the wall. As the temperature increases, the air density decreases and creates a pressure difference along the vertical axis of the pipe. This in turn creates convection currents, and thus the air within the pipe is changed continuously. Although by increasing the diameter, the absorbed radiation is increased, the stack effect is enhanced. Furthermore, the pressure drop for pipes with larger diameter is decreased, and so the vertically induced convection currents are not restrained. The currents enhance heat transfer by convection, a primary requirement in radiation shield design. This effect causes the temperature of the air within the pipe to be closer to the true air temperature. When the pipe used was small (both in length and diameter), the temperature difference was higher since the pressure difference induced across the pipe was low and having a smaller cross-sectional area, ventilation was suppressed.

To further increase convective heat transfer, the pipe was cut resulting in a shield consisting of an open vertical circular channel as shown in Figure $3 \mathrm{~b}$. The aperture angle of $110^{\circ}$ was designed to make sure that solar irradiance never falls on the inner surface of the pipe. Similar to the previous shield, the lowest 
temperature difference achieved when using the open pipe was reached by the larger pipe. The temperature reading recorded when using the open pipe shield $(\mathrm{L}=100 \mathrm{~mm}, \varnothing 50 \mathrm{~mm})$ was closer by a further $50 \%$ when compared to the full pipe having the same dimensions.

The thermocouple inside the open pipe was then painted white in order to reduce its absorptivity. The emissivity of a white surface (90\%) is much higher than that of polished copper (3\%). The thermocouple was painted white to reduce the heat transfer by radiation from the inner surface of the pipe wall to the surface of thermocouple wire. However, since the temperature of the outer surface was not high due to its high reflectivity, the infrared radiation emitted by the inner surface was not intense. This could be observed from the results plotted in Graph 5. The difference between the results for the longer pipe is insignificant. In this case where the white painted thermocouple was not exposed to direct radiation, the insulating effect exceeded the reflectivity effect of the surface. In fact, a white painted thermocouple in open pipes having small diameter gave a higher temperature reading than the brown bare thermocouple. In pipes having a small diameter, the induced convection currents were low, and so the paint-insulated thermocouple wire did not exchange the heat gained, giving a higher reading. This could also be noted when comparing the shorter pipes in Graph 4 and Graph 5. The reading from the white painted thermocouple was higher due to the insulating effect and lower naturally created convection currents.

Another point to note from the last two graphs is the fact that there is no significant change when the diameter of the open pipe is greater than $32 \mathrm{~mm}$. this shows that the velocity of the convection currents reaches a maximum and so the 'cooling' effect of the thermocouple also reaches a maximum. On the other hand, where the air flow through a full pipe is expected to be less turbulent than that through a vertical open channel, as the diameter is increased, the temperature difference keeps decreasing as shown in Graph 3.

\section{Conclusion}

These results show that a PVC screen is much better to shield thermocouples from solar radiation than a copper shield as suggested in the standard published in 2000 (BS, 2000). Further improvements have been discussed in detail. This paper gives a practical way to measure effectively the temperature of air enclosed in solar thermal applications such as solar heating, solar drying, solar distillation. A thermocouple shielded in a white PVC circular channel, $100 \mathrm{~mm}$ long and $32 \mathrm{~mm}$ in diameter gives a temperature reading which is $1.5 \pm$ $0.71^{\circ} \mathrm{C}$ higher than the true air temperature. This is by far lower than the temperature reading from sensors screened by copper shields which results in a temperature rise of $6-9^{\circ} \mathrm{C}$.

\section{Acknowledgments}

This study is part of a research project on solar distillation funded by the Malta Council for Science and Technology in which the University of Malta is partnered with Water Services Corporation and Solar Desalination Technik.

\section{References}

BS, 2000. BS EN 60068-2-9:2000 - Environmental testing - Part 2: Tests - Guidance for solar radiation testing, British Standards.

BS, 2011. BS EN 60068-2-5:2011- Environmental testing: Part 2-5: Tests — Test Sa: Simulated solar radiation at ground level and guidance for solar radiation testing, British Standards.

Campbell, S., 2010. Campbell Scientific - Unaspirated Radiation Shields MET20. 
Erell, E., V. Leal, et al., 2003. On the Measurement of Air Temperature in the Presence of Strong Solar Radiation. Proceedings of the Fifth International Conference on Urban Climate, Lodz, Poland.

Holman, J. P., 2001. Experimental Methods for Engineers,7th ed. McGraw Hill, New York.

Recktenwald, G., 2010. Conversion of Thermocouple Voltage to Temperature. Portland, Portland State University.

WMO, 2008. Guide to Meteorological Instruments and Methods of Observation. Geneva, Switzerland World Meteorological Organization 